\title{
DESENVOLVIMENTO DE SISTEMA DE IGNIÇÃO EMERGENCIAL PARA OS FLARES DE GÁS DE ALTO FORNO DA THYSSENKRUPP CSA (TKCSA)*
}

Claudio José Martins da Silva Ricardo Rodrigues da Silva² Alessandro Maia de Andrade ${ }^{3}$ Luiz Carlos Cardozo 4

Resumo

A planta siderúrgica da TKCSA possui em seu sistema de distribuição de gás dois flares (bleeders) que possuem funções distintas durante o regime normal de operação. O flare 2 é responsável por queimar o gás de alto forno de baixo poder calorífico, gerado no início do processo de partida do alto-forno até que o gás atinja as características adequadas para o aproveitamento e ser direcionado para o gasômetro. Já o flare 1 trabalha em conjunto com o gasômetro no processo de controle de pressão e vazão excedente de gás, quando da redução intempestiva de consumo de gás de alto forno. O presente trabalho apresenta a solução implantada pela TKCSA para garantir, sob quaisquer condições de fornecimento de energia elétrica, a operação dos equipamentos elétricos e de todo o sistema de automação e controle operacional dos flares. Podemos dizer que a operação do flares torna-se autônoma e relação ao sistema elétrico e sistema de automação e controle da distribuição de gás de alto forno. O sistema implantado promoveu uma elevação na segurança operacional dos flares, já que, a autonomia operacional impede o apagamento da chama eliminado a possibilidade de lançamento de gás cru na atmosfera.

Palavras-chave: Segurança; Flare; Emergência; Gás de alto forno.

\section{DEVELOPMENT OF EMERGENCY IGNITION SYSTEM FOR BLAST FURNACE} GAS FLARES OF THYSSENKRUPP CSA (TKCSA)

\section{Abstract}

The steel plant TKCSA has in its gas distribution system two flares (bleeders) that have distinct functions during normal operation conditions. The flare 2 is responsible for the start up of blast furnace when the gas of low calorific value, generated at the beginning of the process starting from the blast furnace until the gas reaches the appropriate characteristics for use and be directed to the flare. The flare 1 is in line with the gas system gasholder in control process pressure and excess gas flow when the untimely reduce consumption of blast furnace gas. This paper presents the solution implemented by CSA to ensure, under all conditions of supply of electricity, operation of electrical equipment and system-wide automation and operational control of flares. We can say that the operation of flares becomes autonomous and relationship to the electrical system and automation control and distribution of blast furnace gas system. The system deployed promoted an increase in operational safety flares since the operational autonomy prevents shutdown of the flame and blocking the possibility of release of raw gas in the atmosphere.

Keywords: Safety; Flare; Emergency; Blast furnace gas.

1 Eng. Elétrico, Eng. Especialista em Manutenção Elétrica, TKCSA, Rio de Janeiro, RJ, Brasil; claudio.martins@thyssenkrupp.com.

2 Eng. de Controle e Automação, Eng. Automação, TKCSA, Rio de Janeiro, RJ, Brasil; ricardo.rodrigues@thyssenkrupp.com.

3 Eng. Mecânico, Eng. Mecânico, TKCSA, Rio de Janeiro, RJ, Brasil; alessandro.andrade@thyssenkrupp.com.

4 Técnico eletrônico, Eletricista de Manutenção, TKCSA, Rio de Janeiro, RJ, Brasil; luiz.cardozo@thyssenkrupp.com.

* Contribuição técnica ao $35^{\circ}$ Seminário de Balanços Energéticos Globais e Utilidades e $29^{\circ}$ Encontro de Produtores e Consumidores de Gases Industriais, 13 a 15 de agosto de 2014, São Paulo, SP, Brasil. 
Seminário de Energia \& Utilidades

$35^{\circ}$ Seminário de Balanços Energéticos
Globais e Utilidades \& $29^{\circ}$ Encontro de Globais e Utilidades \& $29^{\circ}$ Encontro de
Produtores e Consumidores de Gases Industrials

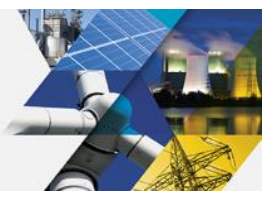

\section{INTRODUÇÃO}

\subsection{Aproveitamento de gases combustíveis na Thyssenkrupp Companhia Siderúrgica do Atlântico (TKCSA)}

O processo de recuperação dos gases gerados nos altos fornos e aciaria, juntamente com a geração de vapor de alta pressão na coqueria, permite a geração de $410 \mathrm{MW}$ médios e fornecimento de gases combustíveis para o processo de fabricação do aço.

Os gases de alto forno (BFG) e aciaria (BOF) são armazenados nos gasômetros que tem função armazenagem, controle de pressão e distribuição dos gases conforme a necessidade dos diversos consumidores internos, garantindo assim o aproveitamento energético dos mesmos evitando assim que os gases sejam queimados diretamente na atmosfera através dos flares (bleeders). Minimizando assim os efeitos do efeito estufa.

\subsection{Flares de gás de Alto forno}

\subsubsection{Características técnicas e principais componentes}

A TKCSA possui dois flares, cada um para uma capacidade de $460.000 \mathrm{Nm}^{3} / \mathrm{h}$ $\left(2 \times 230.000 \mathrm{Nm}^{3} / \mathrm{h}\right)$. Um flare é instalado dentro da área conhecida como gás system, outro flare é instalado na área dos alto-forno. Ambos os flares são idênticos e participam do processo de forma diferenciada (Figura 1).

Cada flare é projetado para os seguintes dados gerais:

Fluxo de Gás do AF: 2 × 230.000 Nm3/h = 460.000 Nm3/h

Pressão de Gás do AF: 130 mbar $(\mathrm{g})$

Temperatura de Gás do AF: $40-55^{\circ} \mathrm{C}$

BFG LHV, base seca: $829 \mathrm{kcal} / \mathrm{Nm3}=3.469 \mathrm{~kJ} / \mathrm{Nm} 3$.

Análise BFG, base seca: $\quad \mathrm{H} 2=3.1 \mathrm{Vol} . \%$

$\mathrm{CO}=24,8 \mathrm{Vol} . \%$

$\mathrm{CO} 2=22,7 \mathrm{Vol} . \%$

$\mathrm{N} 2=49,0$ Vol. $\%$

Condições Mín. do Gás AF: $\quad$ LHV $\geq 600$ kcal/Nm3

Cada sistema flare é composto pelos seguintes equipamentos principais:

- Duas pernas de queima

- Quatro queimadores por perna do queima, totalizando oito

- Duas válvulas borboleta de controle e desligamento

- Um sistema hidráulico para válvulas e controle

- Uma chaminé de tocha

- Sistema de gás piloto (instalado em um container)

- Sistema de ar de combustão

- Cabine de controle local (instalada no container)

O sistema de ar de combustão e o sistema hidráulico são instalados dentro da base da chaminé do flare. A base é isolada do gás contido na parte do gás (entrada de gás do AF) da chaminé por uma placa de cobertura inclinada. - A seção inferior da placa de cobertura é conectada com um tubo para um aparelho separador de condensado na medida em que o condensado e drenado.

* Contribuição técnica ao $35^{\circ}$ Seminário de Balanços Energéticos Globais e Utilidades e $29^{\circ}$ Encontro de Produtores e Consumidores de Gases Industriais, 13 a 15 de agosto de 2014, São Paulo, SP, Brasil. 


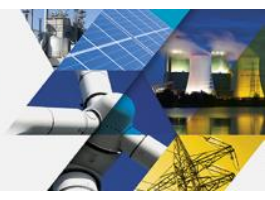

A cabine de controle local é basicamente usada para troca de sinais com o sistema de controle principal no alto-forno. Os sinais são disponibilizados por meio de blocos de Entrada/Saída instalados no local.

FLARE 1

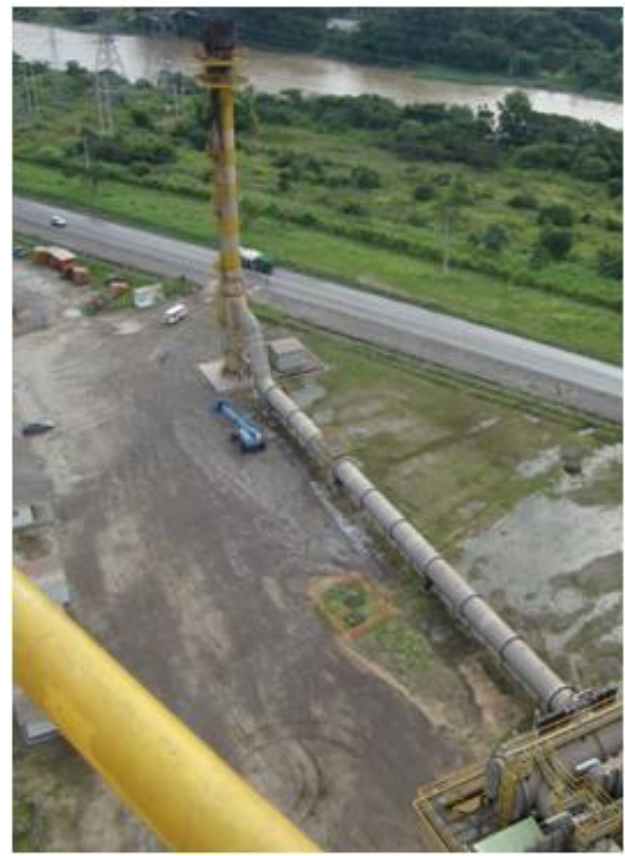

Figura 1 - Vista aérea da área dos flares

\section{FLARE 2}

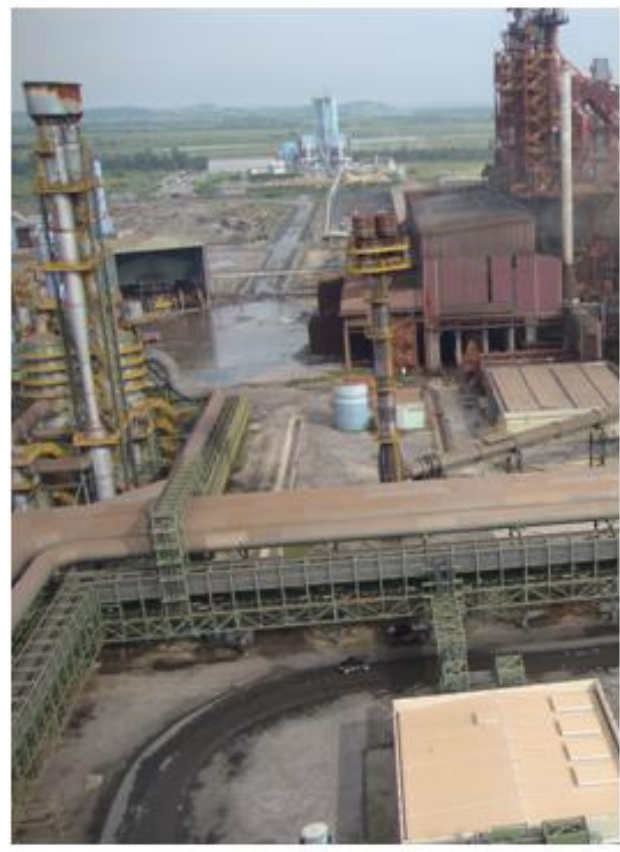

\subsubsection{Sistema elétrico supridor de energia dos flares}

O sistema supridor de energia elétrica é composto de dois alimentadores de 460 $\mathrm{V}$ e dois alimentadores de $220 \mathrm{~V}$. A operação é somente com 01 dos alimentadores fornecendo energia e o segundo alimentador energizado e em "stand by".

$\mathrm{Na}$ falha de um dos alimentadores um sistema automático de transferência efetua a troca de alimentador e mantém o fornecimento de energia para os componentes do flare.

\subsubsection{Função dos flares no processo de distribuição do BF}

A principal função dos flares é queimar o excesso de gás BFG em situações de desbalanço entre suprimento e consumo de gás desbalanceamento o equilíbrio. O segundo objetivo flare é atuar como dispositivo de segurança, liberando o gás do alto-forno no caso da pressão determinada do gás de alto-forno ser excedida. A chama é conectada à rede de gás, onde um controlador de fluxo e um controlador de pressão são instalados. De acordo com o sinal de um dos controladores, a válvula borboleta abaixo do tubo do queimador abre para liberar o gás do alto-forno como previsto no sistema de gás do alto-forno.

\subsubsection{Operação dos flares - monitoração e controle}

As seguintes funções principais da tocha são controladas / monitoradas:

- Pressão de gás natural, pelo controlador de pressão

- Pressão de gás natural, pelas chaves de pressão

- Queimadores piloto, pelos termopares

* Contribuição técnica ao $35^{\circ}$ Seminário de Balanços Energéticos Globais e Utilidades e $29^{\circ}$ Encontro de Produtores e Consumidores de Gases Industriais, 13 a 15 de agosto de 2014, São Paulo, SP, Brasil. 


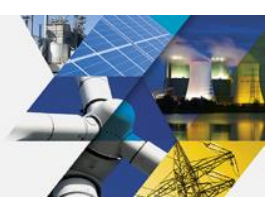

- O controle de pressão do gás de Alto Forno e o controle de fluxo, a partir do sistema de gás de Alto Forno fora da tocha

- Posição de desligamento e válvulas borboletas de controle, pelo transdutor de medição de posição angular e chaves limitadoras

- Ventiladores de combustão de ar ligado / desligado

- Pressão do ar de combustão por chaves de pressão

Caso dois dos mesmos indicarem mais do que $150 \stackrel{\circ}{\mathrm{C}}$ a tocha principal de gás do alto-forno é considerada como queimando.

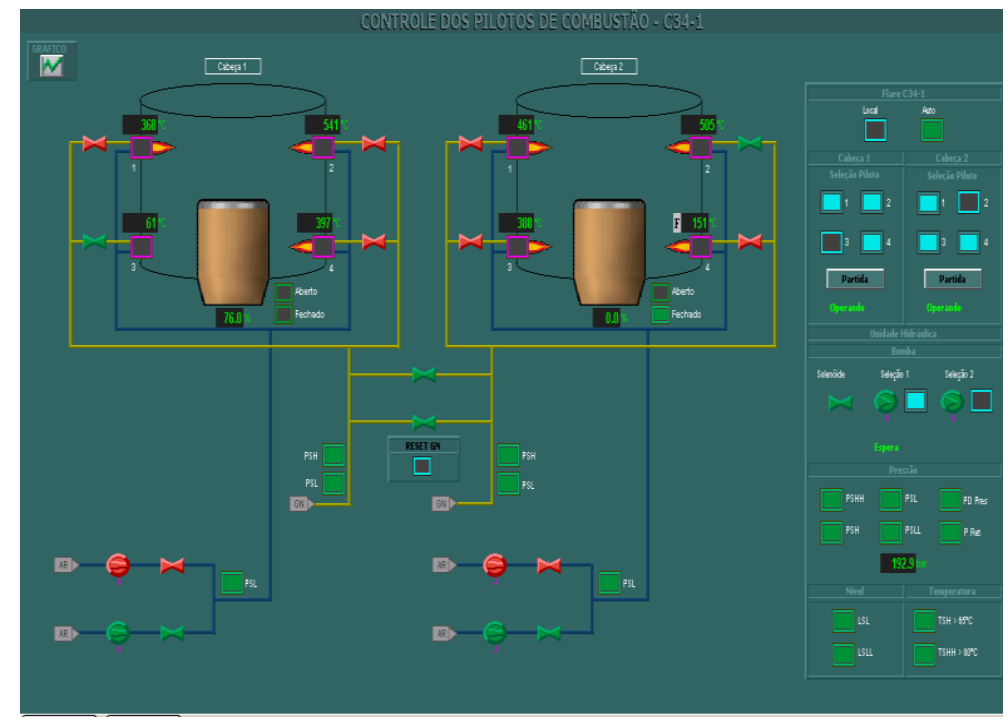

Figura 2 - Visão geral do controle das cabeças de queima

\subsubsection{Falhas de operação dos flares}

Já ocorreram duas situações de emergência onde os flares ficaram inoperantes: 1ㅁ - Falha de comunicação entre o PLC ABB e a cabeça remota ABB existente em cada flare, apesar dos circuitos de comunicação redundantes (falha dos processadores do PLC ABB); e

$2^{\mathrm{a}}$ "Apagão" do sistema de energia ocorrido no Site.

Em caso de pane nos flares, seja por falha de comunicação ou apagão, a abertura das válvulas de controle seria, em último caso, por pressão, que já operou várias vezes desde a partida do Gas System.

Embora o sistema de válvulas com contrapesos resolva inteiramente o problema de alívio e controle da pressão na linha de BFG, a injeção de gás BFG sem queima na atmosfera representa riscos imediatos de vida tão grandes que tornam os riscos de contaminação secundários.

Devido a estas ocorrências, detectou-se a necessidade de incorporar ao sistema de flares recursos que garantam a queima do gás BFG mesmo em caso de uma destas falhas.

\subsubsection{Solução para a partida do flare em caso de falha}

A solução ideal seria a de se colocar um PLC seguro (SIL 3) nos containers dos flares, transferindo para estes toda a operação dos mesmos, incluindo controle de pressão, controle de posição das válvulas, comandos de seleção e operação de queimadores, etc. Nesta configuração, o PLC da área do sistema de gases apenas se comunicaria com os PLCs dos flares. Em caso de falha de 
Seminário de

Energia \& Utilidades

$35^{\circ}$ Seminário de Balanços Energéticos

Globais e Utilidades \& $29^{\circ}$ Encontro de

Produtores e Consumidores de Gases Industrial

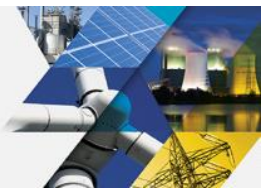

comunicação e/ou apagão, os PLCs dos flares seguiriam um procedimento de emergência específico.

Porém, esta é uma solução inviável, tanto devido aos custos da solução a nível dos flares, como também da interferência e modificações necessárias no programa do PLC do Gas System. Além disso, o prazo de implantação seria muito longo.

Definimos então pela implantação de um sistema de controle Dual ao existente.

\section{MATERIAIS E MÉTODOS}

\subsection{Desenvolvimento do sistema partida emergencial do flare}

Para garantir a queima de todo e qualquer gás BFG que deixe os flares é preciso agir rapidamente, garantindo a queima daquele gás. Para isso, entendemos serem necessários os seguintes passos, em cada um dos flares, em caso de falta de comunicação ou apagão.

A primeira fase do projeto foi estabelecer propostas de solução a serem implantadas, sendo a proposta B com instalação de UPS para alimentação do sistema elétrico de 220 Volts e gerador diesel para alimentação em 460 Volts.

Tabela 1 - Quadro de Proposta de solução

\begin{tabular}{|c|c|c|}
\hline Proposta A & Proposta B & Proposta C \\
\hline $\begin{array}{l}\text { Acionamento de } 1 \text { soprador e } 2 \text { pilotos } \\
\text { (por cabeça), através de painel elétrico } \\
\text { utilizando como alimentador uma fonte } \\
\text { de alimentação confiável (Gerador - } 460 \\
\text { VAC), sendo este painel totalmente } \\
\text { independente do painel do Flare. }\end{array}$ & $\begin{array}{l}\text { Acionamento de } 2 \text { pilotos (por } \\
\text { cabeça), através de painel } \\
\text { elétrico utilizando como } \\
\text { alimentador uma UPS - } 230 \\
\text { VAC, sendo este painel } \\
\text { totalmente independente do } \\
\text { painel do Flare. O suprimento } \\
\text { de ar de combustão, será } \\
\text { substituído por ar comprimido. }\end{array}$ & $\begin{array}{l}\text { Construção de novas redes de GN } \\
\text { + Ar comprimido para alimentar } 2 \\
\text { novos pilotos, com painel dedicado } \\
\text { para alimentação dos ignitores. }\end{array}$ \\
\hline $\begin{array}{l}\text { Vantagens: } \\
\text { - Praticamente nenhuma } \\
\text { modificação de ordem } \\
\text { mecânica }\end{array}$ & $\begin{array}{l}\text { Vantagens: } \\
\text { - Utilização de UPS de } \\
\quad \text { pequeno porte } \\
\text { - } \quad \text { Custo baixo }\end{array}$ & $\begin{array}{l}\text { Vantagens: } \\
\text { - Utilização de UPS de } \\
\text { pequeno porte } \\
\text { - Sistema totalmente } \\
\text { independente, não } \\
\text { necessitando de alteração } \\
\text { no projeto original }\end{array}$ \\
\hline $\begin{array}{l}\text { Desvantagens: } \\
\text { - } \quad \text { Alto consumo de energia, } \\
\text { sendo necessário uma fonte de } \\
\text { energia de médio porte } \\
(\text { 20KVA) para garantir a } \\
\text { alimentação dos sopradores } \\
\text { (cada soprador } 2,2 \mathrm{~kW}) \\
\text { - } \quad \text { Pouco de espaço no } \\
\text { - container elétrico já existente } \\
\text { Custo muito elevado }\end{array}$ & $\begin{array}{l}\text { Desvantagens: } \\
\text { - Nenhuma }\end{array}$ & $\begin{array}{l}\text { Desvantagens: } \\
\text { - Necessidade de } \\
\text { implementação das novas } \\
\text { redes na estrutura do } \\
\text { Flare } \\
\text { - Custo elevado }\end{array}$ \\
\hline
\end{tabular}

Estabelecido um escopo de necessidade contratamos uma empresa para desenvolver e implantar as alterações no sistema atual fornecendo o serviço e os materiais necessários a implantação seguiu um cronograma de 04 meses.

* Contribuição técnica ao $35^{\circ}$ Seminário de Balanços Energéticos Globais e Utilidades e $29^{\circ}$ Encontro de Produtores e Consumidores de Gases Industriais, 13 a 15 de agosto de 2014, São Paulo, SP, Brasil. 
Seminário de Energia \& Utilidades

$35^{\circ}$ Seminário de Balanços Energéticos

Globais e Utilidades \& $29^{\circ}$ Encontro de

Produtores e Consumidores de Gases Industrials

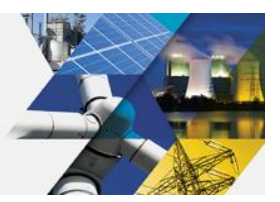

Tabela 2- Cronograma de implantação

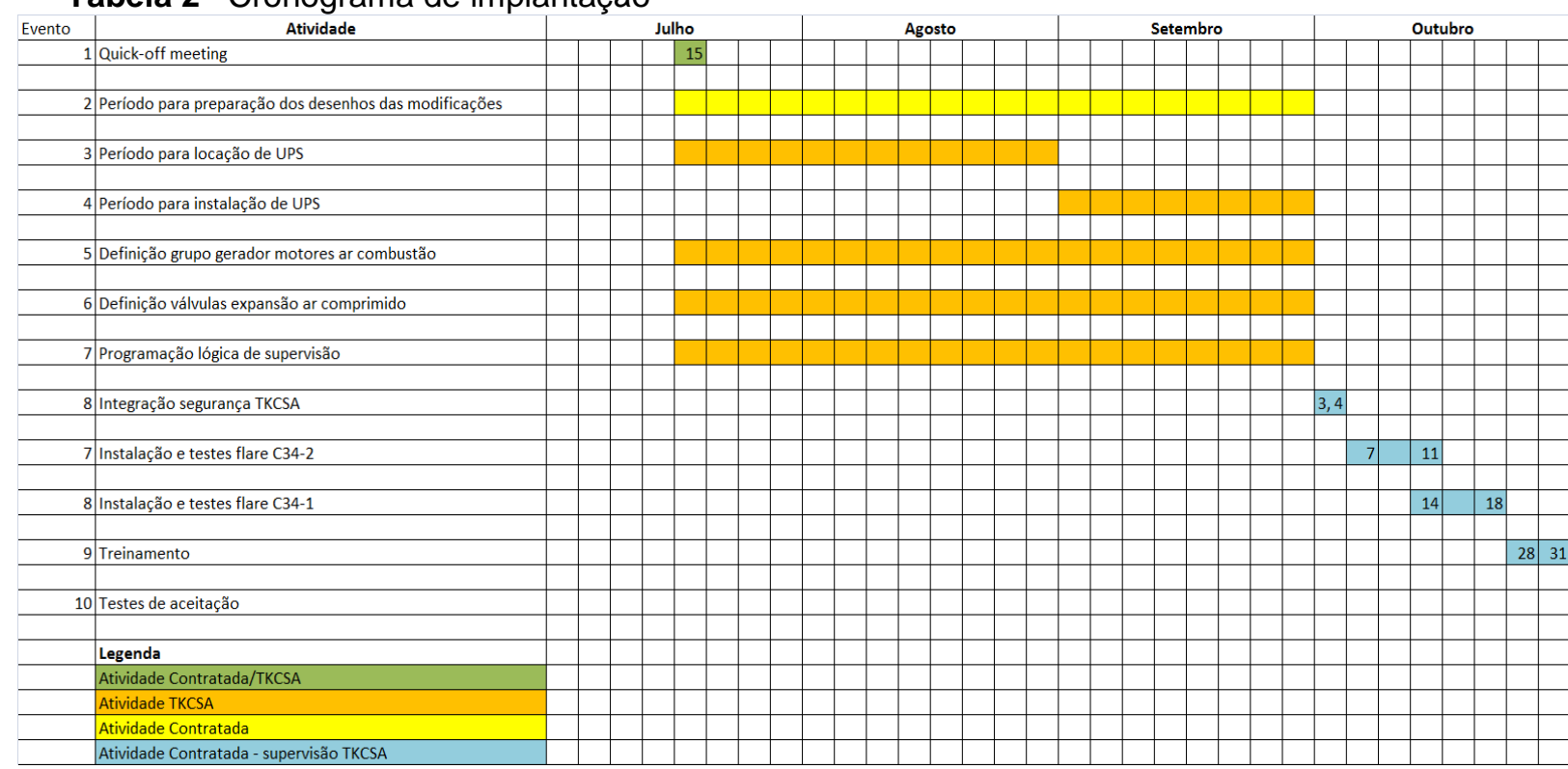

\subsection{Principais funcionalidades do sistema}

Abertura de uma válvula solenoide do circuito de ar comprimido da TKCSA, através de uma válvula de expansão redutora de pressão, para garantir um fluxo mínimo de ar de combustão (sugestão da própria TKCSA). A instalação desta válvula é opcional, cabendo à TKCSA definir e realizar sua instalação;

Partida imediata dos 2 motores de ar de combustão de cada cabeça;

Troca da alimentação dos centelhadores dos pilotos para alimentação proveniente de UPS, com isolação galvânica.

Abertura da válvula solenoide by-pass de alimentação de gás natural;

Abertura das duas válvulas solenoide de ar de combustão;

Abertura das válvulas solenoide dos quatro queimadores de gás natural daquela cabeça;

Sequenciamento dos ignitores, deixando cada um deles ligado por 3 segundos. Com isto, o ciclo de trabalho dos ignitores será de $25 \%$, e cada ignitor receberá uma nova descarga após 9 segundos. Este sequenciamento visa garantir que todos os queimadores se manterão acesos, mesmo que venham a apagar devido a vento, fluxo violento de gás BFG, baixa vazão de ar de combustão, etc.

Partida do grupo gerador diesel de apoio, que supriria a energia necessária para restaurar o ar de combustão por ventilação forçada e a alimentação dos circuitos dos flares. O grupo gerador é uma opção a ser avaliada e instalada pela TKCSA.

\subsection{Funcionamento do sistema de emergência}

O programa de controle do PLC do Gas System deverá sofrer uma pequena modificação, Deverá ser incluída uma pequena lógica de controle que gera uma onda quadrada com uma frequência de $1 \mathrm{~Hz}$. Este sinal será propagado para uma saída digital reserva em um módulo D0810, tanto no flare 1 quanto no flare 2.

Estas saídas estarão em ciclo constante (onda quadrada) a uma frequência de $1 \mathrm{~Hz}$. Cada um destes sinais será levado até cada uma das placas do sistema de emergência (Figura 3), no sinal OK.

* Contribuição técnica ao $35^{\circ}$ Seminário de Balanços Energéticos Globais e Utilidades e $29^{\circ}$ Encontro de Produtores e Consumidores de Gases Industriais, 13 a 15 de agosto de 2014, São Paulo, SP, Brasil. 




O PLC da placa Sistema de Emergência manterá suas saídas de controle (descritas abaixo) inativas enquanto o sinal de $1 \mathrm{~Hz}$ proveniente do PLC da ABB estiver presente. Caso este sinal fique inativo por 2 segundos, a placa de controle começara a piscar o sinalizador vermelho, e caso o sinal ABB OK não retorne dentro destes 5 segundos, a sequência de emergência será iniciada, desde que o bloco BLK esteja em seu lugar.

Uma vez transcorridos os cinco segundos de espera, a sequência de emergência será ativada.

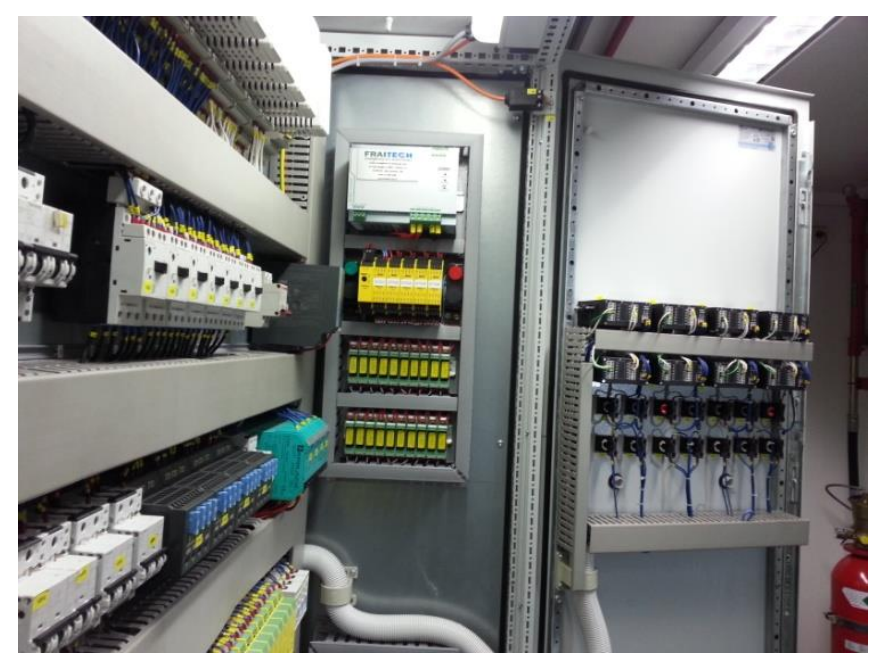

Figura 3 - Visão geral dos componentes

A sequência de emergência consta de passos onde são confirmados a realização de todas as etapas de operação dos componentes do flare:acionamento

- Alimentação secundária da ignição dos queimadores,

- Abertura da válvula principal de gás natural,

- Partida do motores de ar de combustão;

- Abertura das válvulas solenoides de ar de combustão;

- Abertura das válvulas de gás natural das cabeças do flare;

- Liga e desliga ignição do queimador dos queimadores;

A placa Sistema de Emergência manterá a sequência da ignição dos queimadores indefinidamente. A sequência das ignições visa reacender queimadores que se apaguem, seja por baixa vazão de ar de combustão, ventos fortes, vazão violenta de gás BFG, etc.

Mesmo que o PLC do sistema de gás volte a enviar regularmente o sinal de 1 $\mathrm{Hz}$, a placa Sistema de Emergência não devolverá o controle ao sistema convencional. Para que isto ocorra, as seguintes condições deverão ser satisfeitas:

1. PLC do sistema de gás deverá estar enviando o sinal de $1 \mathrm{~Hz}$ até a placa do sistema de emergência;

2. Um operador, localmente, deve pressionar simultaneamente as duas botoeiras RST da placa do sistema de emergência: 
Seminário de

Energia \& Utilidades

$35^{\circ}$ Seminário de Balanços Energéticos

Globais e Utilidades \& $29^{\circ}$ Encontro de

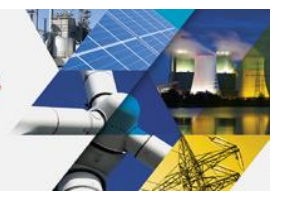

\subsection{Interface com o sistema supervisório}

Cada placa de controle do Sistema de emergência envia sinais para o PLC do sistema de controle de gases (Figura 4) e foi necessário alterações na lógica para permitir:

- Lógica para gerar os sinais de OK do PLC para as placas do sistema de controle

- Lógica para detectar e indicar:

- Se as placas Sistema de Emergência estão OK, com blobo BLK encaixado

- Se as placas Sistema de Emergência estão com override ativo.

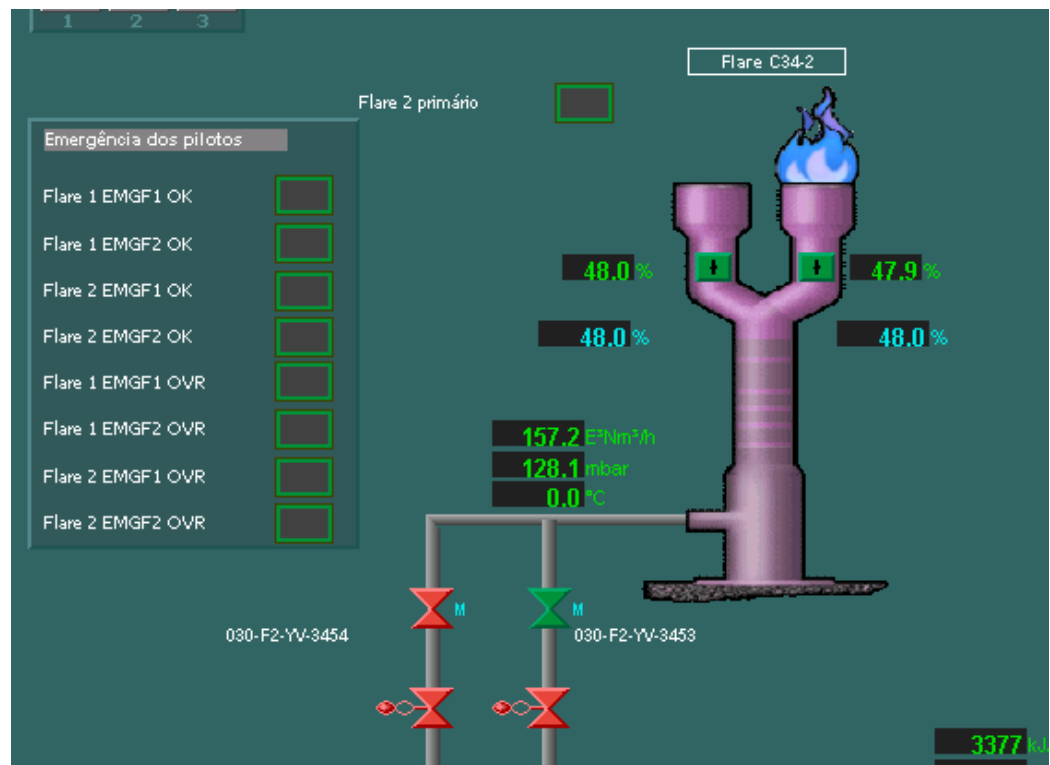

Figura 4 - Indicadores de estado na tela dos Flares de AF

\subsection{Sistema elétrico de emergência}

Para o sistema de 220V volts uma UPS de 2300 VA (Figura 5) foi instalada e passa a ser a fonte de energia para a s cargas. Na falta de tensão a UPS fornece energia por cerca de 40 minutos às cargas emergências.

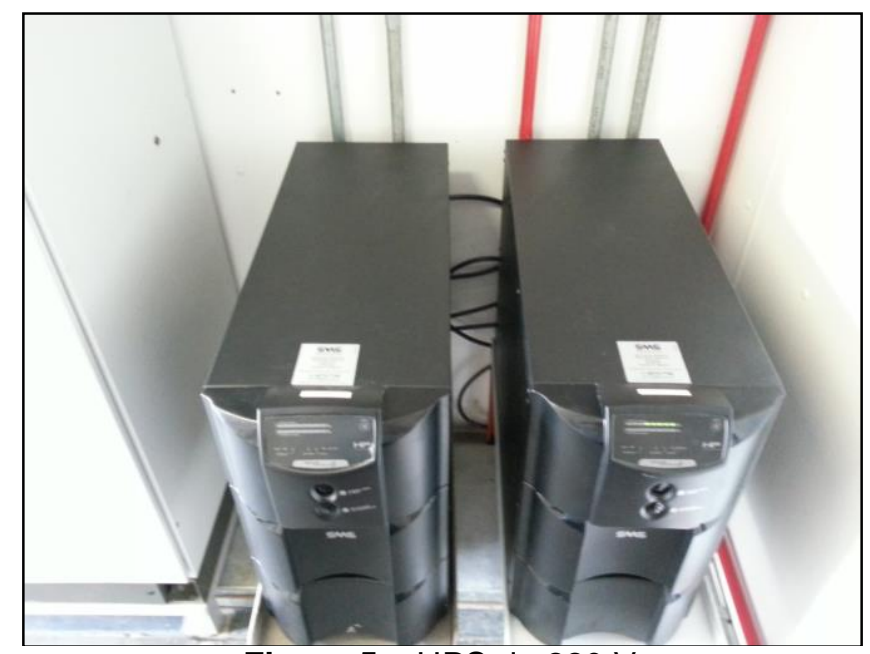

Figura 5 - UPS de $220 \mathrm{~V}$

* Contribuição técnica ao $35^{\circ}$ Seminário de Balanços Energéticos Globais e Utilidades e $29^{\circ}$ Encontro de Produtores e Consumidores de Gases Industriais, 13 a 15 de agosto de 2014, São Paulo, SP, Brasil. 


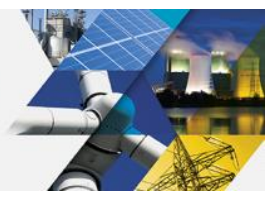

Para o sistema de $460 \mathrm{~V}$ um gerador com um quadro de transferência automática foi conectado entre os alimentadores existentes e o painel do flare.

A operação segura do gerador é garantida através da garantia das mesmas características elétricas do sistema através de verificação que o gerador fornecerá a mesma sequencia de fases

(Figura 6). Com isso garantimos a correta operação de motores, ventiladores e bombas durante a entrada em operação do sistema de emergência.



Figura 6 - Teste de sequência de fases do gerador

\section{RESUSTADOS}

\subsection{Testes funcionais a quente}

Para a certificação do sistema implantado estabelecemos uma estratégia de testes baseada em criar condições de falha/ desligamento dos alimentadores de energia elétrica em 460 Volts para os flares (Figura 7).

Através do painel de transferência de alimentador elétrico realizamos todas possíveis situações de emergência de perda de alimentação elétrica e resposta do sistema de emergência,

a. Perda de um alimentador e entrada em operação e partida e alinhamento do gerador.

b. Perda do $2^{\circ}$ alimentador e transferência da alimentação para o gerador

c. Perda dos dois alimentadores simultaneamente, transferência da alimentação para o gerador e partida em emergência do flare.

d. Retorno do alimentador e saída de operação do gerador

* Contribuição técnica ao $35^{\circ}$ Seminário de Balanços Energéticos Globais e Utilidades e $29^{\circ}$ Encontro de Produtores e Consumidores de Gases Industriais, 13 a 15 de agosto de 2014, São Paulo, SP, Brasil. 

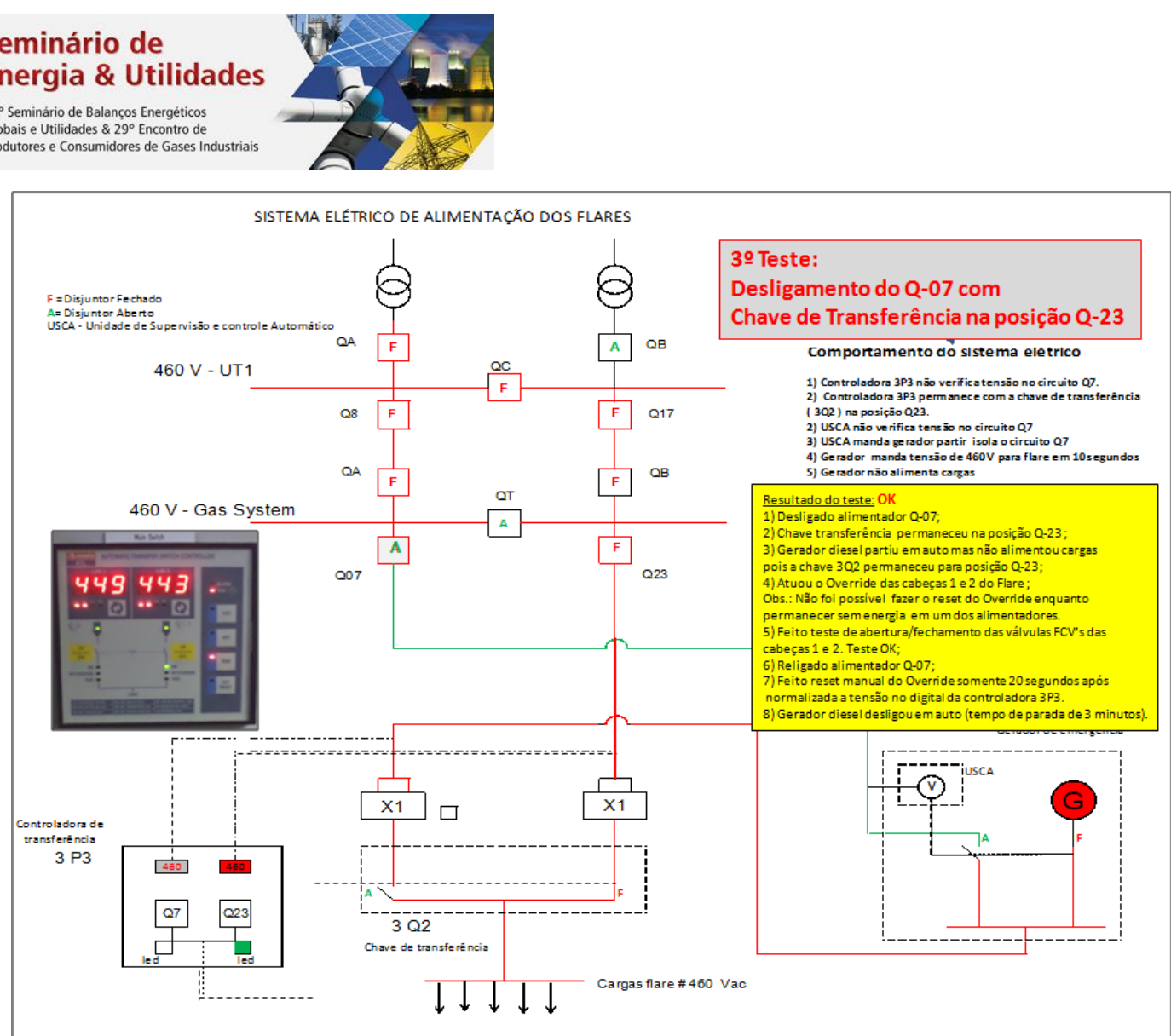

Figura 7 - exemplo de teste operacional do sistema de emergência

\subsection{Resultado dos testes}

Os testes foram considerados satisfatórios e o comportamento do sistema elétrico do Flare atuou conforme preconiza o projeto. Foi constatado que quando ocorrer falta de energia em um dos alimentadores (Q-07 ou Q-23) do container do Flare, ocorre a atuação dos sistemas de "override" do controle do Flare, ou seja, o sistema de ignição de emergência entrará em operação mesmo que o supervisório 800xA esteja normal.

A controladora de transferência deverá operar sempre em modo automático, pois ela que controlará a chave de transferência e esta determinará a qual conexão alimentador de 460V o flare estará conectado, seja via CCM do Gas System ou Gerador Diesel de Emergência.

O "override" do sistema de emergência do Flare 1 só pode ser feito após 20 segundos da tensão de 460V estar normalizada nos dois alimentadores (Q-07 e Q-23).

Foi constatado que o Gerador Diesel de Emergência leva 3 minutos para efetuar a parada automática após partida quando for solicitada.

Importante: Quando for ser feito o desligamento programado de um ou dos 2 alimentadores do Flare para manutenção deve ser desligado também o sistema de ignição de emergência.

\section{CONCLUSÃO}

A adoção da Proposta de solução B teve sua eficiência confirmada durante a realização dos testes sendo atendidas as premissas estabelecidas na proposta. Durante os testes de comissionamento do sistema de emergência garantiu-se a correta operação do sistema, porém, devido às circunstâncias estabelecidas

* Contribuição técnica ao $35^{\circ}$ Seminário de Balanços Energéticos Globais e Utilidades e $29^{\circ}$ Encontro de Produtores e Consumidores de Gases Industriais, 13 a 15 de agosto de 2014, São Paulo, SP, Brasil. 


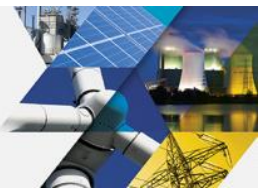

para realização dos testes não temos o efeito surpresa de uma situação emergencial.

Atualmente não podemos permitir por sequer um instante condições inseguras em nosso ambiente interno à fábrica quanto que atinja a comunidade que nos cerca.

\section{Agradecimentos}

Agradecemos a toda equipe de operação e manutenção da área de distribuição de utilidades que apoiaram e nos ajudaram na viabilização da implantação dos componentes e geradores de emergência. Bem como, nos apoiaram na realização dos testes operacionais, garantindo assim que o sistema de emergência tivesse todas as suas funcionalidades operando corretamente.

A Empresa FRAITECH com seu profissionalismo conseguiu no entregar o sistema pronto para os testes dentro dos prazos do cronograma.

\section{REFERÊNCIAS}

1 Man Ferrostaal. Manual de operação do sistema de gás da Thyseenkrupp CSA. 2010.

2 Man Ferrostsal. Manual de operação do sistema do flare da Thyseenkrupp CSA. 2008.

3 Man Ferrostsal. Descritivo funcional do sistema do flare da Thyseenkrupp CSA. 2007.

4 Man Ferrostsal. Diagrama elétrico do flare da Thyseenkrupp CSA. 2007.

5 Fraithec. Manual de Operação do Sistema de Emergência dos Flares. Outubro 2013.

* Contribuição técnica ao $35^{\circ}$ Seminário de Balanços Energéticos Globais e Utilidades e $29^{\circ}$ Encontro de Produtores e Consumidores de Gases Industriais, 13 a 15 de agosto de 2014, São Paulo, SP, Brasil. 